\title{
It is Time: A Commentary on "An Exploration of Genetic Counselors' Needs and Experiences with Prenatal Chromosomal Microarray Testing"
}

\author{
Krista Redlinger-Grosse
}

Received: 1 April 2014 / Accepted: 9 April 2014 / Published online: 2 May 2014

(C) National Society of Genetic Counselors, Inc. 2014

In “An Exploration of Genetic Counselors' Needs and Experiences with Prenatal Chromosomal Microarray Testing," Bernhardt et al. (2014) investigated the use of chromosomal microarray analysis (CMA) in prenatal diagnosis from a unique vantage point - that of the genetic counselor. CMA is just one of the growing number of options for patients on the prenatal screening/diagnosis "menu." As these options increase, inevitably comes the risk for uncertain results. Through examining the experiences of genetic counselors who have counseled patients about uncertain prenatal microarray results, Bernhardt et al. (2014) concluded that genetic counselors are interested (and need) education and training on how to manage these uncertain results. While I emphatically agree, I find myself wondering if this call is of broader significance - a need to better adopt, train/educate and support the counseling within genetic counseling.

First, let me openly state my bias. As a genetic counselor for over 10 years, who is now pursuing a doctoral degree in counseling psychology, I value the recognition of the inherent psychosocial needs of our patients. I also strongly believe that we need to acknowledge the inevitable impact that addressing these psychosocial needs has on us as counselors. Thus, I was struck by the way in which Bernhardt et al. (2014) findings support these very notions.

As a profession, we have developed our own practice model-the Reciprocal Engagement Model (REM) of Genetic Counseling - that supports balancing our educational responsibilities alongside of our counseling and supportive roles (McCarthy Veach et al. 2007; Hartman et al. 2013). And yet, empirical evidence indicates that we continue to

K. Redlinger-Grosse $(\bowtie)$

Department of Educational Psychology, University of Minnesota, 250 Education Sciences Building, 56 E. River Road, Minneapolis, MN 55455, USA

e-mail: redli009@umn.edu operate out of a "teaching" role (Meiser et al. 2008). Studies such as Bernhardt et al. (2014) suggest that a predominantly teaching role is not going to be sustaining for either our patients, or ourselves. Uncertainty is just one of the many psychological issues that will continue to emerge with the increasing utilization of complex genetic technologies. Confusion, worry, grief/loss, depression, marital stress - the list is likely unlimited. It is time for genetic counselors to step in and be "active" counselors in our work with our patients. Through interventions such as shared decision-making, we can demonstrate our unique skill set that enables us to address our patients' emotional needs, while at the same time providing patient-centered information and education.

And yet what holds us back? We could endlessly hypothesize explanations - an inordinate amount of genetic information to present, inadequate time, lack of support structures, heavy caseloads, and/or a need for better psychosocial training and education. It is this latter factor that Bernhardt et al. (2014) discusses and I find intriguing. On one hand, we promote psychosocial skills and development through the practicebased competencies that inform our training programs (Accreditation Council for Genetic Counseling 2013), yet on the other hand, we have evidence that development of psychosocial skills within clinical rotations is not always emphasized or supported (Biesecker 2003; Borders et al. 2006; Weil 2003). Kessler (1997) also states, "Unfortunately, genetic counseling students largely have been taught to be active teachers, but passive counselors" (p. 390). The end result is a vicious (and I would argue an unsatisfactory) circle where trainees and genetic counselors alike are not taking risks and utilizing their psychosocial skills. Without practice these skills can become uncomfortable and intimidating. Sadly, Bernhardt et al. (2014) results suggest that it is not just the patients who may suffer, but also the genetic counselors. We need training, education, and supervision/consultation (Zahm et al. 2008) at all levels of experiences - from trainees to seasoned genetic 
counselors - on how to overcome psychosocial discomfort and intimidation.

In addition, I propose that we need to reframe for ourselves the ways in which we offer psychological counseling to our patients. As I work with genetic counseling students, I have observed how the very notion of "being psychosocial" is intimidating. They seem to imagine that implementation of their counseling skills translates into tackling long-term, psychosocial concerns that they are neither equipped nor trained to handle. I suspect they are not alone with this concern and that experienced genetic counselors grapple with the similar fears. I would argue, however, that psychosocial counseling for genetic counselors has a different process (e.g., brief, present focused), as well as a more specific outcome goal (e.g., decision-making, acceptance of genetic diagnosis, communication of genetic information). Jon Weil (Personal communication, October 2, 2008) coined the terms little and big psychosocial issues as a way to frame the psychological areas of expertise of genetic counselors versus psychologists. He proposes that genetic counselors work with their patients on "smaller, immediate, interactional aspects" (i.e., little psychosocial issues) of counseling; in contrast, the larger, longer-term big psychosocial issues such as "marital discord, significant anxiety or depression" are better addressed in long-term counseling with psychologists. When viewed this way, psychological counseling in genetic counseling can be more attainable, less anxiety producing, and fit within our shortterm model.

In summary, it is time for genetic counselors to be reminded about and brought back to the counseling in genetic counseling. Bernhardt et al. (2014) study demonstrates that genetic counselors are grappling with the psychosocial uncertainty that technologies such as CMA bring to not only their patients, but themselves. As our profession continues to define and document our unique value within healthcare, we must continue to foster our counseling identity as this, along with our genetic expertise, sets us apart from other specialties.
Bernhardt et al. (2014) remind us that now is the time to do this - for not just our patients, but also our profession.

Conflicts of Interest Krista Redlinger-Grosse declares that she has no conflict of interest.

\section{References}

Accreditation Council for Genetic Counseling. (2013). Practice based competencies for genetic counselors. Retrieved on February 26, 2014 from http://gceducation.org/Documents/ACGC\% 20Practice\%20Based\%20Competencies_13-Final-Web.pdf

Bernhardt, B. A., Kellom, K., Barbarese, A., Faucett, W. A., \& Wapner, R. J. (2014). An exploration of genetic counselors' needs and experiences with prenatal chromosomal microarray testing. Journal of Genetic Counseling. doi:10.1007/s10897014-9702-y.

Biesecker, B. B. (2003). Back to the future of genetic counseling: commentary on "psychosocial genetic counseling in the postnondirective era." Journal of Genetic Counseling, 12, 1-5.

Borders, D., Eubanks, S., \& Callanan, N. (2006). Supervision of psychosocial skills in genetic counseling. Journal of Genetic Counseling, $15,211-223$.

Hartman, J. M. C., Veach, P., MacFarlane, I., \& LeRoy, B. (2013). Genetic counselor perceptions of genetic counseling session goals: a validation study of the reciprocal-engagement model. Journal of Genetic Counseling. doi:10.1007/s10897-013-0647-6.

Kessler, S. (1997). Psychological aspects of genetic counseling. X. Advanced counseling techniques. Journal of Genetic Counseling, 6, 279-391.

McCarthy Veach, P., Bartels, D., \& LeRoy, B. (2007). Coming full circle: a reciprocal-engagement model of genetic counseling practice. Journal of Genetic Counseling, 16, 713-728.

Meiser, B., Irle, J., Lobb, E., \& Barlow-Stewart, K. (2008). Assessment of the content and process of genetic counseling: a critical review of empiric studies. Journal of Genetic Counseling, 17, 434-451.

Weil, J. (2003). Psychosocial genetic counseling in the post-nondirective era: a point of view. Journal of Genetic Counseling, 12, 199-211.

Zahm, K., McCarthy Veach, P., \& LeRoy, B. (2008). An investigation of genetic counselor experiences in peer group supervision. Journal of Genetic Counseling, 17, 220-233. 